\title{
A Study of the Susceptibility of Anopheles species to Pyrethroids on Long Lasting Insecticide Treated Nets (LLINs) and Ownership and Usage of LLINs in Some Communities in Obi Local Government Area
}

\author{
Victor Ugochukwu OBISIKE*1, Emmanuel Ogilegwu OGBU ${ }^{2}$ and Elizabeth U AMUTA ${ }^{3}$ \\ ${ }^{1}$ Department of Animal and Environmental Biology, Abia State University, Uturu. Abia, Nigeria \\ ${ }^{2}$ Department of Biological Sciences, Benue State University Makurdi. Benue, Nigeria
}

${ }^{3}$ Department of Zoology, Federal University of Agriculture Makurdi .Benue, Nigeria

*Corresponding author: Victor Ugochukwu OBISIKE, Department of Animal and Environmental Biology Abia State University,

Uturu. Abia, Nigeria, Email: talk2vu@gmail.com

ARTICLE INFO

Received: 㓞 September 25, 2020

Published: 慧 October 06, 2020

Citation: Victor Ugochukwu OBISIKE, Emmanuel Ogilegwu OGBU, Elizabeth U AMUTA. A Study of the Susceptibility of Anopheles speciesto Pyrethroids on Long Lasting Insecticide Treated Nets (LLINs) and Ownership and Usage of LLINs in Some Communities in Obi Local Government Area. Biomed J Sci \& Tech Res 31(1)-2020. BJSTR. MS.ID.005033.

Keywords: Anopheles mosquitoes; Pyrethroids; Long Lasting Insecticide Treated Nets; Obi

\begin{abstract}
The use of Long-Lasting Insecticide-treated Nets (LLINs) for Malaria vector control depends entirely on the continued susceptibility of Anopheles mosquitoes to pyrethroid Insecticides. This research is aimed at comparing the susceptibility of Anopheles species to pyrethroids on Long Lasting Insecticide-treated Nets in Okpokwu, Adiko and Obarike communities of Obi Benue State, Nigeria. LLINs of ages 0 (control nets), 1, 2, 3, 4, years were collected from each of the three communities. Anopheles larvae were also collected from the three communities, reared to adulthood from April-June 2015. Emerged adult female mosquitoes were tested for susceptibility to pyrethroids on each of the net ages collected. The mosquito in total were susceptible to pyrethroids on LLINs, with a mortality rate of $98.5 \%$. The highest mortality, $100 \%$ was recorded in Adiko community, 98\% mortality in Obarike community and the lowest, 97.6\% mortality in Okpokwu community. The relationship between the mortality of mosquitoes and the different study communities was not significant. Mosquito samples were susceptible to net ages 0,1 and 2 years with mortality rates of $100 \%$ each; $98 \%$ mortality with net age 3 years and $94 \%$ mortality with net age 4 years. The relationship between the mortality of mosquitoes and the different net ages was significant $(\mathrm{P}<0.05)$. Out of 316 individuals that responded to questionnaires, a total of 279 (88.3\%) owned LLINs out of which only 177 (63.4\%) used LLINs previous night before this study. There was a significant relationship between the ownership and utilisation of LLINs with respect to the communities $(r=0.99)$, occupation $(r=0.94)$, age $(r=0.99)$ and gender $(r=1)$ of the respondents. This study concluded that mosquito populations from Obi LGA are susceptible to pyrethroids on LLINs indicating that LLINs are veritable tools for malaria control.
\end{abstract}

\section{Background of Study}

Malaria is one of the most important vector-borne parasitic diseases worldwide [1]. Malaria is one of the most widespread infectious diseases of our time, threatening the health of about two-third of the world's human population in 106 countries and territories; and resulting in as much as 600 million clinical attacks and taking the lives of more than 650,000 people a year, most of them in sub-Saharan Africa [1]. Malaria is the 3rd leading cause of death for children under five years worldwide, after pneumonia and diarrheal disease. One thousand three hundred young lives are estimated to be lost to malaria every day [2]. Malaria is a major public health problem in Nigeria where it accounts for more cases and deaths than any other country in the world. Malaria is a risk for 
$97 \%$ of Nigeria's population. The remaining $3 \%$ of the population live in the malaria free highlands [3]. There are an estimated 100 million malaria cases with over 300,000 deaths per year in Nigeria. Malaria is the commonest cause of outpatient attendance across all age groups with about $66 \%$ of clinic attendance thus constituting a huge burden on the economy of Nigeria [4]. Nigeria accounted for $27 \%$ of malaria cases and $24 \%$ of malaria deaths globally in 2016 [5]. Anopheles gambiae is the primary mosquito vector responsible for transmission of malaria in most of sub-Saharan Africa [6,7]. Malaria vector control programmes in Africa rely heavily on the use of pesticides for insecticide-treated nets (ITNs)/long-lasting insecticide-treated nets (LLINs) and for indoor residual spraying (IRS) [8]. The use of these strategies is known to contribute to the reduction in malaria transmission $[9,10]$. The effectiveness of the current vector control depends much on the susceptibility of the local malaria vectors to insecticides used [8]. The emergence of resistance of these vectors to this insecticides have become one of the greatest challenges to these strategies and to the vision of future eradication of malaria infection as well as a threat to the global health of populations especially in tropical and subtropical regions of the world.

\section{Materials and Methods}

\section{Study Area}

The study was carried out in Obi Local Government Area (LGA) of Benue State between the months of April to June 2015. Obi LGA is located between latitude $6^{0} 56^{\prime \prime}$ and $7^{0} 10^{\prime \prime} \mathrm{N}$ and longitude $8^{0} 10^{\prime \prime}$ and $8^{\circ} 20^{\prime \prime}$ E, covering an expanse area of about $516 \mathrm{~km}^{2}$ and situated at the South-Central part of Benue State. By the year 2015, the population of Obi is estimated to be 128075 with $3 \%$ growth rate [11]. Adiko, Okpowu-ito and Obarike were the communities in Obi L.G.A. that were used for the study. Obi Local Government Area lies in the Southern Guinea Savannah biome which is a transitional zone between the Northern Sudan Savannah and the forest belt of the South with its characteristic coarse grasses and numerous species of scattered trees widely developed as park-land.

The climate of the area falls within the tropical wet and dry climatic belt designated "AW". The climate can be described as tropical sub-humid type with two distinct seasons: wet and dry seasons. Rainfall averages 8 months annually between April and November with totals ranging between 1200-2000mm, though subject to seasonal variation which may lead to either earlier or later rains, in 2015 rain began in the month of February. The annual dry season in the area lasts four to five months. Temperature is relatively high over the area throughout the year averaging $28^{\circ} \mathrm{C}$ $32^{\circ} \mathrm{C}$ with an occasional peak at $37^{\circ} \mathrm{C}$ between March and April. This is combined with an average relative humidity (RH) of over $80 \%$ in the morning and falls to between $50 \%$ and $70 \%$ in the afternoon. The people of Obi L.G.A. speak Igede and are predominantly farmers with maize, cassava, rice, groundnuts, and yams the main farm produce (Figures 1,2).

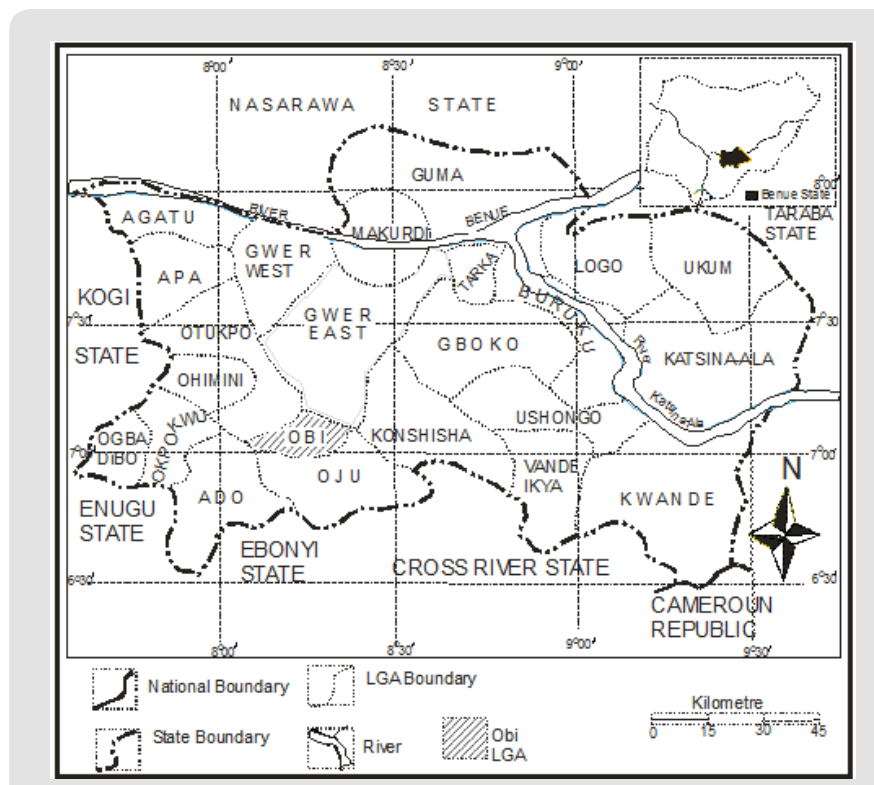

Figure 1: Map of Benue State Showing Obi LGA.

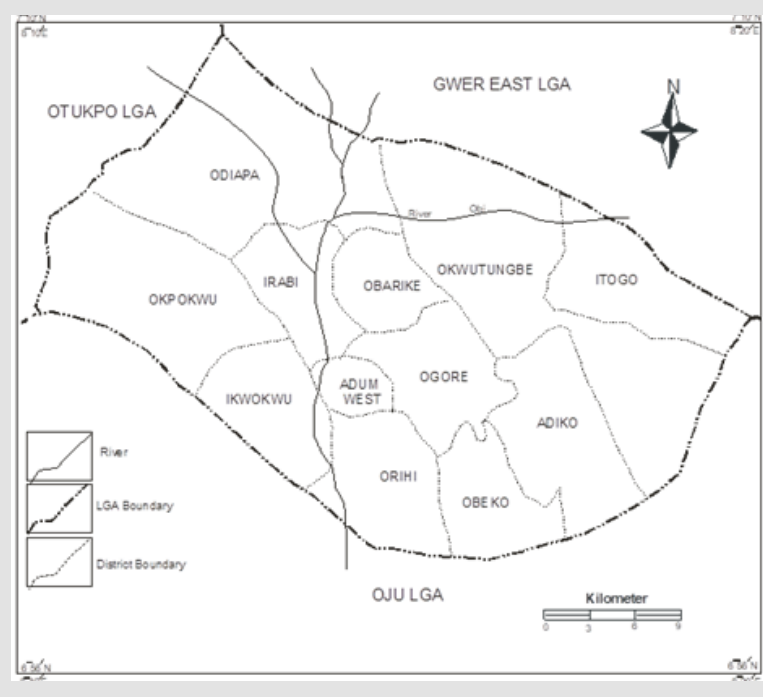

Figure 2: Map of Obi LGA showing study Areas.

\section{Ethical Consent}

A letter of introduction was obtained from the Department of Biological Sciences, Benue State University, Makurdi for the purpose of the research. Permission was obtained from the Community Heads of the three communities where the study was carried out. Volunteered participants were briefed on the relevance of the research, after which they orally indicated their consent.

\section{Materials}

Materials that was used for the study includes; Questionnaires, Long Lasting Insecticide-treated nets, Insect cages (16 x 16) inches, Cone-test kits [12,13], Aspirator, Dipper/Scooping spoon, Plastic containers, Yeast/liver powders, Cotton wool, Glucose solution. 


\section{Methods}

\section{Collection of LLINs}

A total of 15 LLINs were used in this study. Five LLINs of different ages 0, 1yr, 2yrs 3yrs and 4yrs were randomly collected from different households in each of the three different communities. Age 0 nets were unused nets that served as the control nets while the rest of the nets were being used in the communities. These nets were replaced by new ones for each one that was collected.

\section{Net Cages}

Three cages were built (16 x 16 inches). One for vector samples from each of the communities.

\section{Larval Collection and Rearing of Anopheles Species}

Field Anopheles larval collection was done in natural larval breeding sites in the three selected communities between the months of April and June 2015. Anopheles larvae were identified based on their position on water which was parallel to water surface while the pupae are comma-shaped when viewed from the side. Collection was done using a collecting spoon. Care was taken in other not to disturb the larvae. The larvae and pupae were collected with breeding site water and transferred into plastic containers that were well labelled with the names of the three different communities. The plastic containers were uncovered to allow air so that the larvae and pupae can breathe while they were being transported to the laboratory. Yeast/liver powder which served as feed to the larvae and pupae was spread on the surface of the plastic containers. This was done moderately to avoid pollution of water and mortality. The water in the container was monitored regularly and as soon as it is noticed to be polluted it was changed to avoid high mortality. Pieces of cotton wools soaked in sugar solution and gently squeezed to drain out excess solution was placed in the cage at various location the sugar solution served as feed to the adult stage that emerged [12-14].

\section{Sorting of Mosquitoes}

Sorting out of Adult female Anopheles species from the males was done by simple observation using major differentiating morphological characteristics according to Gilles and Coetzee [6] such as the palps not swollen at the end and the antennae nonplumose for the females while the for the males the palps are swollen and the antennae plumose in nature. The females were sucked out using an aspirator.

\section{Bioassay}

Cone-test: The knock down (KD) effects of pyrethroids on the nets collected were tested using test kits (WHO cone) and standard procedures as recommended by the World Health Organization/ World Health Organization Pesticide Evaluation Schemes [1214]. Pieces of nets $25 \mathrm{~cm}$ by $25 \mathrm{~cm}$ were carefully cut out from the old nets of different ages and firmly placed on the wall in the laboratory. The cone was placed on the nets to be tested; adhesive sponge tapes were used to fix the cones to the wall. Ten batches each of 2-3 days old non-blood fed laboratory bred Adult female Anopheles gambiae mosquitoes were aspirated and transferred into cones. After exposing the mosquitoes for 3 minutes, they were carefully taken out of the cones and transferred to empty cage for observation. The knock down effect of pyrethroids on each of the net age was recorded at 10 minutes interval over a One-hour exposure period. The final mortality was recorded after 24 hours. The experiment was replicated five times for each of the net age collected from households using the same number of mosquitoes. Controls included batches of mosquitoes from each site exposed to unused nets (net age 0 ). The Bioassays was carried out at room temperature. The average knockdown, percentage knockdown and percentage mortality were calculated after the experiment.

\section{Knock-down/Mortality}

Integrated vector management [13] manual and video was used in estimating the knock-down and mortality of the Anopheles mosquitoes.

\section{Statistical Analysis}

Difference in average mortality between the selected communities, across ages of nets $[14,15]$ and criteria for efficacy of at least $>80 \%$ mortality or $>90 \%$ knockdown used to evaluate the resistance/susceptibility status of the mosquitoes tested. Chisquare test and Analysis of Variance were used in analysing the result while Correlation was used in the analysis of questionnaire findings.

\section{Results}

\section{Mosquito Population}

Anopheles gambiae larvae and pupae were found in large populations in the three communities. They were collected more from pools, temporary streams, rice fields and abandoned wells. The mosquitoes were reared in the laboratory between the months of April and June 2015 using Insect cages (16 x 16) inches and Plastic containers.

\section{Susceptibility Test Results: Percentage knockdown and Mortality of Mosquitoes across communities and net ages}

Table 1 shows the overall knockdown of mosquitoes across the communities to be 671 (89.5\%). Adiko community had the highest knockdown of 232 (92.8\%) while Okpokwu community had the lowest knockdown of 208 (83.2\%). There was a significant relationship between locality and knockdown $\left(\chi^{2}\right.$ calculated $=15.648, \mathrm{df}=2, \mathrm{P}<0.05)$. Table 2 shows that the total number of mortality (\%) of mosquitoes recorded across the different communities was 739 (98.5\%). The highest mortality of (100\%) was recorded in Adiko community, while the lowest (97.6\%) was 
at Okpokwu community. The relationship between the mortality of mosquitoes and communities was not significant $\left(\chi^{2}\right.$ calculated $=$ $5.720, \mathrm{df}=2, \mathrm{P}>0.05$ ). Table 3 shows the knockdown of mosquitoes across the different net ages. The highest (100\%) knockdown was recorded with age 0 nets, while the least (68.7\%) knockdown was recorded with age 4 years. There was a significant relationship between the knockdown of mosquitoes and the different ages of the nets that were used for the study $\left(\chi^{2}\right.$ calculated $=105.180, \mathrm{df}=4, \mathrm{P}$ $<0.05$ ). Table 4 . shows the mortality (\%) of mosquitoes across the different net ages. for net ages 0.1 and 2 years $100 \%$ mortality was recorded while $98.7 \%$ and $94.0 \%$ mortality were recorded for net age 3 and 4 years, respectively. The relationship between mortality of mosquitoes and net ages used for the study was significant $\left(\chi^{2}\right.$ calculated 28.048, df = 4, $\mathrm{P}<0.05$ ).

Table 1: Knockdown of Anopheles gambiae Mosquitoes after 60 mins Exposure to LLINs inthree different Communities.

\begin{tabular}{|c|c|c|}
\hline Community & NumberExposed & $\begin{array}{c}\text { Number Knocked } \\
\text { down(\%) }\end{array}$ \\
\hline Okpokwu & 250 & $208(83.2)$ \\
\hline Adiko & 250 & $232(92.8)$ \\
\hline Obarike & 250 & $231(92.4)$ \\
\hline Total & 750 & $671(89.5)$ \\
\hline
\end{tabular}

$(\chi 2$ calculated $=15.648, \mathrm{df}=2, \mathrm{P}<0.05)$

Table 2: Mortality of Anopheles gambiae Mosquitoes after 24 hrs Exposure to LLINs inthree different Communities

\begin{tabular}{|c|c|c|}
\hline Community & NumberExposed & Number Mortality (\%) \\
\hline Okpokwu & 250 & $244(97.6)$ \\
\hline Adiko & 250 & $250(100)$ \\
\hline Obarike & 250 & $245(98)$ \\
\hline Total & 750 & $739(98.5)$ \\
\hline
\end{tabular}

$(\chi 2$ calculated $=5.720, \mathrm{df}=2, \mathrm{P}>0.05)$

Table 3: Knockdown of Anopheles gambiae Mosquitoes after 60 mins Exposure to different ages of LLINs.

\begin{tabular}{|c|c|c|}
\hline Net Age (Years) & NumberExposed & Number Knockdown (\%) \\
\hline 0 & 150 & $150(100)$ \\
\hline 1 & 150 & $148(98.7)$ \\
\hline 2 & 150 & $141(94.0)$ \\
\hline 3 & 150 & $129(86.0)$ \\
\hline 4 & 150 & $103(68.7)$ \\
\hline Total & 750 & $671(89.5)$ \\
\hline
\end{tabular}

$(\mathrm{X} 2$ calculated $=105.180, \mathrm{df}=4, \mathrm{P}<0.05)$

Table 4: Mortality of Anopheles gambiae Mosquitoes after 24 hrs Exposure to different ages of LLINs.

\begin{tabular}{|c|c|c|}
\hline Net Age (Years) & NumberExposed & Number Mortality (\%) \\
\hline 0 & 150 & $150(100)$ \\
\hline 1 & 150 & $150(100)$ \\
\hline 2 & 150 & $150(100)$ \\
\hline
\end{tabular}

\begin{tabular}{|c|c|c|}
\hline 3 & 150 & $148(98.7)$ \\
\hline 4 & 150 & $141(94.0)$ \\
\hline Total & 750 & $739(98.5)$ \\
\hline
\end{tabular}

$(\chi 2$ calculated $=105.180, \mathrm{df}=4, \mathrm{P}<0.05)$

\section{Findings on Ownership, Utilisation and Handling Practices of LLINs}

Findings on the ownership, utilisation and handling practices of LLINs of 316 respondents to administered questionnaires. The overall ownership and utilisation of LLINs across different communities as recorded in Table 5 were 279 (88.3\%) and 102 (63.4\%) respectively. Adiko community had the highest ownership 105 (92.12\%) while Obarike community had the lowest 61 (81.3\%). The highest percentage utilisation was recorded in Obarike community 40 (65.6\%) with Okpokwu community having the lowest 71 (62.8\%). There was a significant relationship between the ownership and utilisation of LLINs with respect to the communities of the respondents $(r=0.99, n=3, P=0.001)$. Information on Table 6 shows that a higher ownership and utilisation of LLINs was recorded amongst the female respondents 205 (96.2\%) and $153(74.63 \%)$ respectively, than their male counterparts with $74(71.8 \%)$ and $24(31.4 \%)$ respectively. There was a significant relationship between the ownership and utilisation of LLINs with respect to the gender of the respondents $(r=1, n=2, P=0.001)$. In relation to the occupation of the respondents the ownership of LLINs as recorded was highest among farmers 142 (96.7\%) and lowest among civil servants 11 (64.7\%) while utilisation was highest among civil servants $9(81.8 \%)$ and lowest among farmers 73 (51.4\%). There was a significant relationship between the ownership and utilisation of LLINs with respect to the occupation of the respondents. $(r=0.94, n=4, P=0.03)$.

Table 5: Ownership and Utilisation of LLINs across different Communities.

\begin{tabular}{|c|c|c|c|}
\hline Communities & $\begin{array}{c}\text { No of } \\
\text { Respondents }\end{array}$ & $\begin{array}{c}\text { Ownership } \\
\text { of LLINs } \\
\text { Number(\%) }\end{array}$ & $\begin{array}{c}\text { Utilisation of LLINs } \\
\text { Number (\%) }\end{array}$ \\
\hline Okpokwu & 127 & $113(89.0)$ & $71(62.8)$ \\
\hline Adiko & 114 & $105(92.1)$ & $66(62.9)$ \\
\hline Obarike & 75 & $61(81.3)$ & $40(65.6)$ \\
\hline Total & 316 & $279(88.3)$ & $177(63.4)$ \\
\hline
\end{tabular}

$(\mathrm{r}=0.99)$

Table 6: Ownership and Utilisation of LLINs with respect to Gender..

\begin{tabular}{|c|c|c|c|}
\hline Gender & $\begin{array}{c}\text { No of } \\
\text { Respondents }\end{array}$ & $\begin{array}{c}\text { Ownership } \\
\text { of LLINs } \\
\text { Number(\%) }\end{array}$ & $\begin{array}{c}\text { Utilisation of LLINs } \\
\text { Number (\%) }\end{array}$ \\
\hline Male & 103 & $74(71.8)$ & $24(31.4)$ \\
\hline Female & 213 & $205(96.2)$ & $153(74.6)$ \\
\hline Total & 316 & $279(88.3)$ & $177(63.4)$ \\
\hline
\end{tabular}

$(\mathrm{r}=1)$ 
In relation to the Age of the respondents as shown in Table 7, the highest percentage of ownership was recorded among the age groups of 25-34 years, 109 (9.6\%), while the lowest was among 65-74years 3 (75\%), of the age group. The highest percentage utilisation was among age group 55-64, 4 (66.7\%) and age groups $65-74,2(66.7 \%)$ while the lowest was among the age group 45-54, 17 (60.7\%) as shown in Table 8. There was a significant relationship between the ownership and utilisation of LLINs with respect to the age of the respondents $(r=0.99, n=7, P=0.001)$. Table 9 shows that majority of the respondents 166 (59.5) that owned LLINs have nets that have lasted $1>2$ years while very few 3 (1.1) have nets that have lasted above 4 years. There was no significant relationship between the communities of the respondents and the ages of LLINs owned by the respondents ( $\chi^{2}$ calculated $\left.=14.282, \mathrm{df}=8, \mathrm{P}>0.05\right)$.
Table 7: Ownership and Utilisation of LLINs in relation to Occupation of Respondents.

\begin{tabular}{|c|c|c|c|}
\hline Occupation & $\begin{array}{c}\text { No of } \\
\text { Respondents }\end{array}$ & $\begin{array}{c}\text { Ownership } \\
\text { of LLINs } \\
\text { Number(\%) }\end{array}$ & $\begin{array}{c}\text { Utilisation of LLINs } \\
\text { Number (\%) }\end{array}$ \\
\hline Traders & 90 & $84(93.3)$ & $67(79.8)$ \\
\hline Farmers & 156 & $142(96.7)$ & $73(51.4)$ \\
\hline Students & 53 & $142(96.7)$ & $28(66.7)$ \\
\hline Civil servants & 27 & $11(64.7)$ & $28(66.7)$ \\
\hline Total & 316 & $279(88.3)$ & $177(63.4)$ \\
\hline
\end{tabular}

$(\mathrm{r}=0.94)$

Table 8: Ownership and Utilisation of LLINs in Relation to Age of Respondents.

\begin{tabular}{|c|c|c|c|}
\hline Age (Years) & No of Respondents & Ownership Number(\%) & Utilisation Number (\%) \\
\hline $0-14$ & 9 & $8(88.9)$ & $5(62.5)$ \\
\hline $15-24$ & 58 & $50(86.2)$ & $32(64)$ \\
\hline $25-34$ & 119 & $109(91.6)$ & $48(64)$ \\
\hline $35-44$ & 84 & $75(89.3)$ & $28(66.7)$ \\
\hline $45-54$ & 33 & $28(84.8)$ & $17(60.7)$ \\
\hline $55-64$ & 9 & $6(66.7)$ & $4(66.7)$ \\
\hline $65-74$ & 4 & $3(75)$ & $2(66.7)$ \\
\hline Total & 316 & $279(88.3)$ & $177(63.4)$ \\
\hline
\end{tabular}

$(\mathrm{r}=0.99)$

Table 9: Duration of Ownership/Net Ages of LLINs across Different Communities.

\begin{tabular}{|c|c|c|c|c|c|c|}
\hline \multirow{2}{*}{ Communities } & \multirow{2}{*}{ No of Respondents } & \multicolumn{5}{|c|}{ Duration of Ownership/Net Ages(\%) } \\
\cline { 3 - 7 } & & $\mathbf{> 1}$ year & $\mathbf{1}$ year + & 2years + & $\mathbf{3}$ years + & $\mathbf{4}$ years + \\
\hline Okpokwu & 113 & $17(15.0)$ & $64(56.6)$ & $23(20.4)$ & $7(6.2)$ & $2(1.8)$ \\
\hline Adiko & 105 & $27(25.7)$ & $59(7.9)$ & $16(62.9)$ & $2(1.9)$ & $1(1.0)$ \\
\hline Obarike & 61 & $12(19.7)$ & $43(70.5)$ & $43(70.5)$ & $0(0.0)$ & $0(0.0)$ \\
\hline Total & 279 & $56(20.1)$ & $166(59.5)$ & $45(16.1)$ & $9(3.2)$ & $3(1.1)$ \\
\hline
\end{tabular}

$\left(\chi^{2}\right.$ calculated $\left.=14.282, \mathrm{df}=8, \mathrm{P}>0.05\right)$

Table 10 shows that majority of the respondents that owned relationship between communities of the respondents and LLINs have never washed them $151(54.1 \%)$ while $1(0.4)$ the frequency of washing LLINs $\left(\chi^{2}\right.$ calculated $=45.319, \mathrm{df}=10, \mathrm{P}<$ respondents washed theirs weekly. There was a significant 0.05).

Table 10: Frequency of Washing LLINs by Respondents across the Different Communities.

\begin{tabular}{|c|c|c|c|c|c|c|c|}
\hline \multirow{2}{*}{ Communities } & & \multicolumn{5}{|c|}{ Frequency of Washing(\%) } \\
\cline { 2 - 8 } & No of Respondents & Never Washed & Once in a week & A month & 3 months & $\mathbf{6}$ months & $\mathbf{1 2}$ months \\
\hline Okpokwu & 113 & $41(36.3)$ & $0(0.0)$ & $17(15.0)$ & $6(5.3)$ & $10(8.9)$ & $39(34.5)$ \\
\hline Adiko & 105 & $71(67.6)$ & $1(1.0)$ & $1(1.0)$ & $5(4.8)$ & $10(9.5)$ & $17(16.2)$ \\
\hline Obarike & 61 & $39(63.9)$ & $0(0.0)$ & $0(0.0)$ & $0(0.0)$ & $7(11.5)$ & $15(24.6)$ \\
\hline Total & 279 & $151(54.1)$ & $1(0.4)$ & $18(6.5)$ & $11(3.9)$ & $27(9.7)$ & $71(25.4)$ \\
\hline
\end{tabular}

$\left(\chi^{2}\right.$ calculated $\left.=45.319, \mathrm{df}=10, \mathrm{P}<0.05\right)$ 
Figure 3 shows that majority of the respondents that own LLINs got them from the free distribution campaign number 303 (96\%) while only $13(4 \%)$ purchased theirs. Information on Figure 4 shows that the major reason why some respondents did not own LLINs was that they sought for nets but were not given, while lack of knowledge of LLINs was not a reason for non-ownership of nets as all the respondents knew about LLINs. Figure 5 shows that the major reasons why the respondents owned nets but did not use them were because of the feeling of heat and discomfort while a few 2 (2.0) and 3 (2.9) complained of suffocation and ineffectiveness.

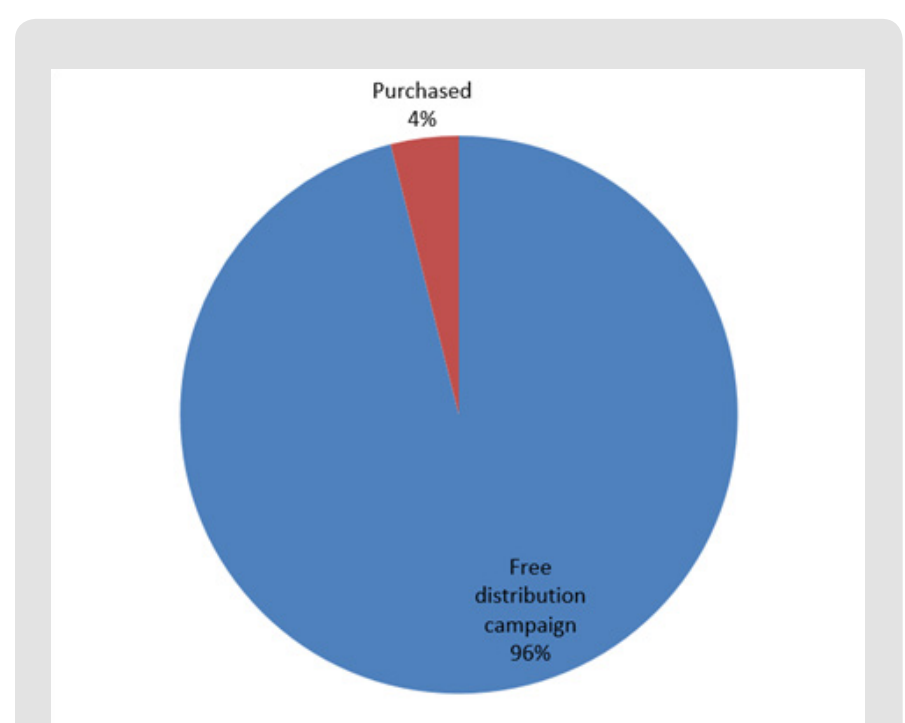

Figure 3: Sources of Long-lasting insecticide nets among respondents in Obi LGA.

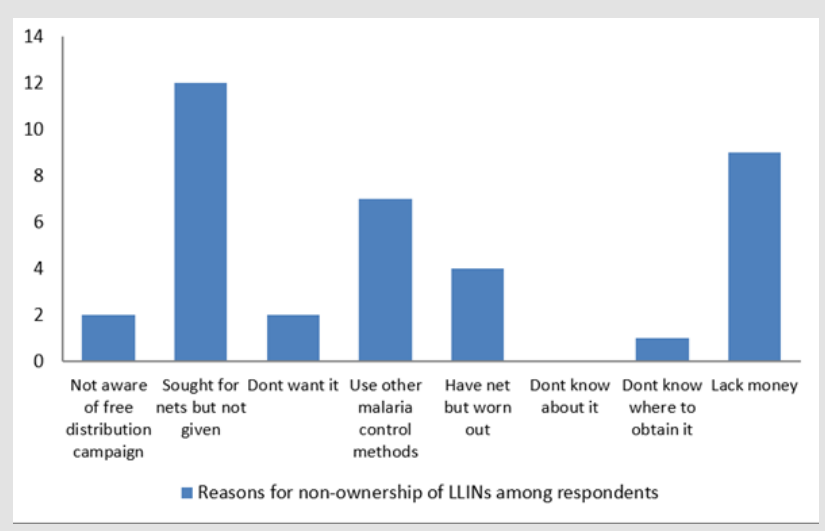

Figure 4: Reasons for non-ownership of LLINs among respondents in OBI LGA.

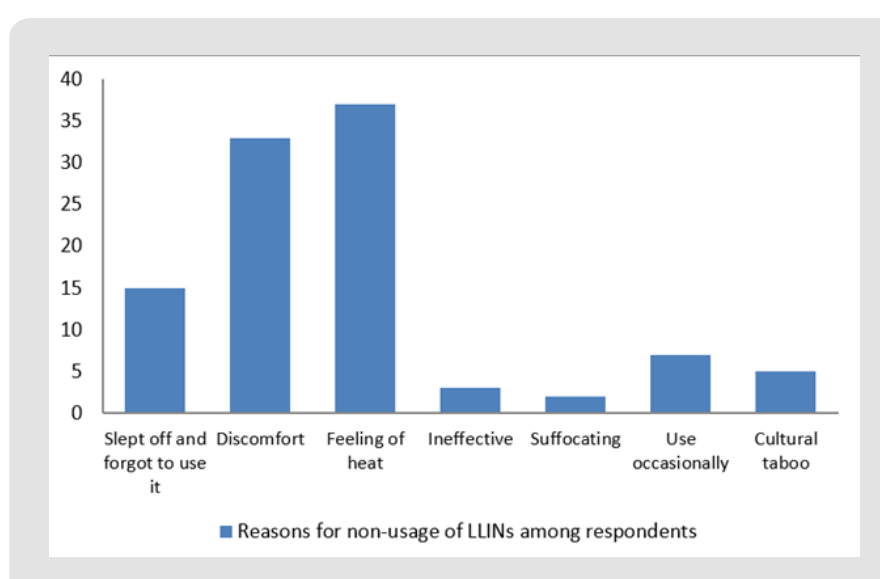

Figure 5: Reasons for non-usage of LLINs among respondents in Obi LGA.

\section{Discussion}

World Health Organisation [15] recommendations for testing susceptibility/resistance states that $98-100 \%$ mosquito mortality indicates susceptibility, $80-97 \%$ suggest potential resistance that needs to be confirmed, and $<80 \%$ mortality suggests resistance. Based on these criteria, the present study overall, showed a full susceptibility of Anopheles gambiae to pyrethroids on LLINs, (98.50\%) which was being used in Obi LGA Area of Benue State. This is like some earlier reports from other parts of the country [16]. However, this study contrasts with studies which reported widespread resistance to pyrethroids in the African malaria vectors [17-21]. The differences in the levels of insecticide susceptibility/ resistance have been explained as probably a reflection of differential selection pressure exerted on field mosquito populations. The primary source of this selection pressure is still unclear although evidence is accumulating to incriminate the agricultural use of insecticides in selection for resistance in malaria vectors [22]. Owing to this explanation the susceptibility but not resistance reported in this study could be attributed to the fact that agricultural activities in Obi LGA are subsistent, hence the use of insecticide have not been extensive enough to cause resistance in malaria vectors.

In this study the community-based report showed a slightly reduced susceptibility of mosquitoes to pyrethroids on LLINs in Okpokwu community (97.60\%) compared to the full susceptibility reported in Adiko, (100\%) and Obarike, (98\%) communities. This could be attributed to the fact that even though insecticides for agricultural purposes have not be used long and extensively enough to cause resistance in malaria vector in Obi LGA, Okpokwu 
community have a higher concentration of agricultural activities due to land availability and fertility. The observed susceptibility of Anopheles gambiae to the different ages of LLINs in this study complies with the reports of WHO in 2005 [12] that LLINs are veritable tools in malaria control and have efficacy in killing and repelling Anopheles gambiae which is the vector of malaria parasites.

The decreasing rate of knockdown and mortality of Anopheles gambiae with increasing ages of the sampled nets (inverse relationship) observed in Tables 3 and 4 of this study are similar to the findings of Obisike in 2014 [14] and this indicates an increase in insecticidal decay as nets gets older. The reduced susceptibility observed in net ages 4 years which records the least knockdown and mortality rate and which also differs significantly from the rest of the net ages, complies with WHO report that LLINs are designed to retain their bio efficacy against vector mosquitoes for at least a period of 3 years under recommendation for use in the field [23].

The overall ownership of LLINs reported in this study was 279 (88.3\%). This coverage rate is higher than the global target of $80 \%$ set in 2005 World Assembly [12] and by Roll Back Malaria Partnership [24]. This report is like [25] earlier study in South West Nigeria who reported $95.30 \%$ household LLINs coverage rate following a free Government distribution campaign. They argued that for coverage targets to be met at all levels, government has to undertake free distribution of nets to households in the community through campaigns and not wait for households to take initiative of purchasing nets on their own. Observations in this study upholds this recommendation because $(96.0 \%)$ of net owners got them from the free government distribution campaign in the community where they reside while only (4.0\%) bought theirs. Result on the ownership and utilisation of LLINs as regards gender showed that female respondents had a higher percentage of ownership and utilisation of LLINs than their male counterparts. This could be explained with the fact that males generally care more about women and children and tend to leave nets to them when they are not enough for everyone in the family. Furthermore, married males may sleep separately from their wives when they have very young children and hence leave the beds with Nets to their wives and children.

With respect to the occupation of the respondents the higher percentage of ownership recorded among farmers could be attributed to the fact that farmers earn less income than civil servants and hence may take more advantage of the free distribution campaign to save cost: Also the higher percentage of utilisation reported amongst civil servants than farmers could be explained as a reason that civil servants that have resorted to using LLINs may be more aware of the importance of using LLINs for malaria control, while the farmers who recorded the lowest percentage of utilisation may out of negligence or other behaviours like forgetfulness not use their Nets. There was a significant relationship between the ownership and utilisation of LLINs with respect to the community, Gender, Occupation and Age of respondents $(\mathrm{P}<0.05)$. The present study established that majority of the respondents $166(59.5 \%)$ that owned LLINs have nets that have lasted $1>2$ years and also majority of the respondents that owned LLINs have never washed them 151 (54.1\%). These facts could account for the reason why mosquitoes exposed to them were highly susceptible, and this complies with of World Health Organization in 2007 [26] recommendations that LLINs should only be washed for at least 20 times during its lasting periods.

\section{Conclusion}

Reliability on LLINs, as effective control methods for malaria infection, depends on the continued susceptibility of Anopheles gambiae to pyrethroids. This study reveals that mosquito samples from Obi LGA are susceptible to pyrethroids on LLINs, despite the use of insecticides for pest control in agricultural activities. This study also reveals that LLINs are the major tools used for the control of malaria in the study area for pest control in agricultural activities. This study also reveals that LLINs are the major tools used for the control of malaria in the study area.

\section{References}

1. (2010) WHO. World malaria report 2010. WHO Global Malaria Programme.

2. (2013) WHO. World Malaria Report 2013.

3. Amagu N, Obisike VU, Amuta EU (2019) The KAPP Study of Malaria and its Prevalence amongst Boarding School Students in Gboko Local Government Area of Benue State, Nigeria. International Blood Research \& Reviews 10(2): 1-7.

4. Amuta EU (2020) The Tyranny of Parasites: An Epidemiological Sojourn in a Sub- Saharan Region. An Inaugural Lecture, Federal University of Agriculture, Makurdi, Nigeria Inaugural lecture series 27.

5. (2018) World Health Organization. Malaria. Fact sheets World Malaria Report.

6. Gillies M, Coetzee M (1987) A Supplement to the Anophelinae of Africa South of the Sahara. Publications of the South African Institute for Medical Research, Johannesburg 55: 1-143.

7. Sinka ME, Bangs MJ, Manguin S, Coetzee M, Mbogo CM, et al. (2010) The dominant Anopheles vectors of human malaria in Africa, Europe and the Middle East: occurrence data, distribution maps and bionomic précis. Parasites and Vectors 3(117).

8. (2012) WHO Global plan for insecticide resistance management in malaria vectors.

9. Lengeler C (2002) Insecticide-treated bednets and curtains for preventing malaria. Cochrane Review (2)

10. Pluess B, Tanser FC, Lengeler C, Sharp, BL (2010) Indoor residual spraying for preventing malaria. Cochrane Database Systematic Review, CD006657.

11. National Bureau of Statistics (2011) Annual abstract of National Bureau of Statitics, Federal Republic of Nigeria pp. 697.

12. (2005) World Health Organization. Guidelines for laboratory and field testing of long-lasting insecticidal mosquito nets. WHO/CDS/WHOPES/ GCDPP/2005.11. Geneva: World Health Organization. 
13. (2010) Project.net (RIT).

14. Obisike VU, Imandeh GN, Amuta EU (2014) Assessment of Susceptibility of Anopheles to Pyrethroids on LLINs. Lambert Academic Publishing. BahnfstraBe, Germany pp. 69.

15. WHO (2006) Pesticides and their application for the control of vestors and pests of public health importance. Geneva: WHO pest evaluation scheme.

16. Olayemi IK, AT Ande, S Chitta, G Ibemesi, VA Ayanwale, et al. (2011) Insecticide susceptibility profile of the principal malaria vector Anopheles gambiae s.l (Diptera: Culicidae). Journal of Vector Borne Disease 48: 109-112.

17. Awolola TS, Brooke BD, Hunt RH, Coetze M (2002) Resistance of the malaria vector Anopheles gambiae s.s. to pyrethroid insecticides, in south-western Nigeria. Annals of Tropical Medicine and Parasitology 96(8): 849-852.

18. Awolola TS, BD, Brooke, LL Koekemoer, M Coetzee (2003) Absence of the $\mathrm{kdr}$ mutation in the molecular ' $M$ ' form suggests different pyrethroid resistance mechanisms in the malaria vector mosquito Anopheles gambiae s.s. Tropical Medicine and International Health 8(5): 420-422.

19. Kristan M, Fleischman H, Della Torre A, Stich A, Curtis CF (2003) Pyrethroid resistance/Susceptibility and differential urban/rura distribution of Anopheles arabiensis and An. gambiae s.s. malaria vectors in Nigeria and Ghana. Medical and Veterinary Entomology 17(3): 326-332.

ISSN: 2574-1241

DOI: $10.26717 / B J S T R .2020 .31 .005033$

Victor Ugochukwu OBISIKE. Biomed J Sci \& Tech Res

CC (P) This work is licensed under Creative

Submission Link: https://biomedres.us/submit-manuscript.php
20. Awolola TS, IO Oyewole, CN Amajoh, ET Idowu, MB Ajayi, et al. (2005) Distribution of the molecular forms of Anopheles gambiae and pyrethroid knock down resistance gene in Nigeria. Acta Tropica 95(3): 204-209.

21. Awolola TS, Oduola OA, Strode C, Koekemoer LL, Brooke B, et al. (2008) Evidence of multiple pyrethroid resistance mechanisms in the malaria vector Anopheles gambiae sensu stricto from Nigeria. Transactions of the Royal Society Tropical Medicine and Hygiene 103(11): 1139-1145.

22. Oduola AO, Obansa JB, Ashiegbu CO, Adeogun AO, Otubanjo, et al. (2010) High level of DDT resistance in the malaria mosquito: Anopheles gambiae s.l. from rural, semi urban and urban communities in Nigeria. Journal of Tropical Public Health 9: 114-120.

23. Ranson H, N Guessan R, Lines J, Moiroux N, Nkuni Z, et al. (2011) Pyrethroid resistance in African anopheline mosquitoes: what are the implications for malaria control? Trends Parasitol 27(2): 91-98.

24. (2008) Roll Back Malaria Partnership. The Global Malaria Action Plan.

25. Adedeji SA, Olatona OS, Alawode G, Onipe AI, Bolarinwa OA, et al. (2014) Ownership and Utilization of Long Lasting Insecticide-treated nets following free distribution campaign in South West Nigeria. Pan African Medical Journal 17(263): 263.

26. (2007) World Health Organization. Insecticide-treated nets: a WHO position statement. Geneva: World Health Organization.

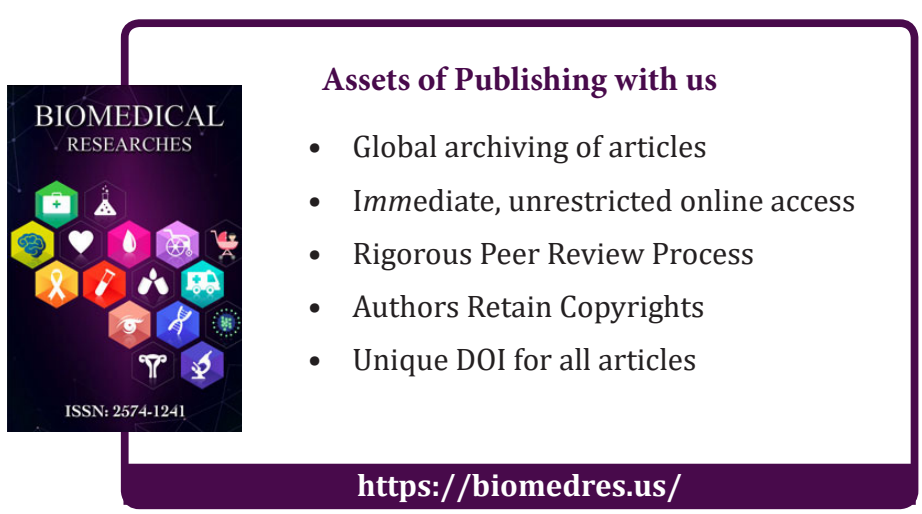


